\title{
TUBEROUS SCLEROSIS COMPLEX WITH RETINAL ASTROCYTIC HAMARTOMAS: A CASE REPORT
}

G. Premalatha ${ }^{1}$, V. Rajeswara Rao ${ }^{2}$, K. Padmavathi ${ }^{3}$

\section{HOW TO CITE THIS ARTICLE:}

G. Premalatha, V. Rajeswara Rao, K. Padmavathi. "Tuberous Sclerosis Complex with Retinal Astrocytic Hamartomas: A Case Report". Journal of Evolution of Medical and Dental Sciences 2015; Vol. 4, Issue 55, July 09; Page: 9689-9693, DOI: $10.14260 /$ jemds/2015/1400

INTRODUCTION: Tuberous sclerosis is a rare syndrome and estimated incidence is 1 in 6000 to $1 \mathrm{in}$ 10,000 live births. The name is derived from the characteristic tuber like growth occurring in brain which calcifies with age and become sclerotic. This was once known as epiloia or Bournville's disease, first identified by French physician Bournville in 1880.

Family history positive in $50 \%$ of patients with autosomal mode of inheritance. Some acquire through a process called gonadal mosaicism. TSC is caused by defects or mutations in one/two of the two genes- TSC1 and TSC-2. The TSC-1 gene is located on chromosome 9(9q34) and produces protein called hamartin. The TSC-2 gene is on chromosome 16(16p 13.3) and produces tuberin.

Ophthalmic manifestations include hamartomas of the iris, ciliary body(1) and retina.Retinal astrocytic hamartomas are glial tumors of the retinal nerve fiber layer that arise from retinal astrocytes. Classically they appear as a cream-white, well-circumscribed, elevated lesion that may present as multiple or solitary sites.

CASE REPORT: A 32yr female patient presented with abdominal pain and swelling. She was referred from medical ward for ophthalmic examination.

Clinical examination of the patient revealed presence of facial haemangiomas appearing as well defined roughly round to oval dark brown firm papules on both side of the cheeks in a butterfly fashion and huge right and left flank mass.

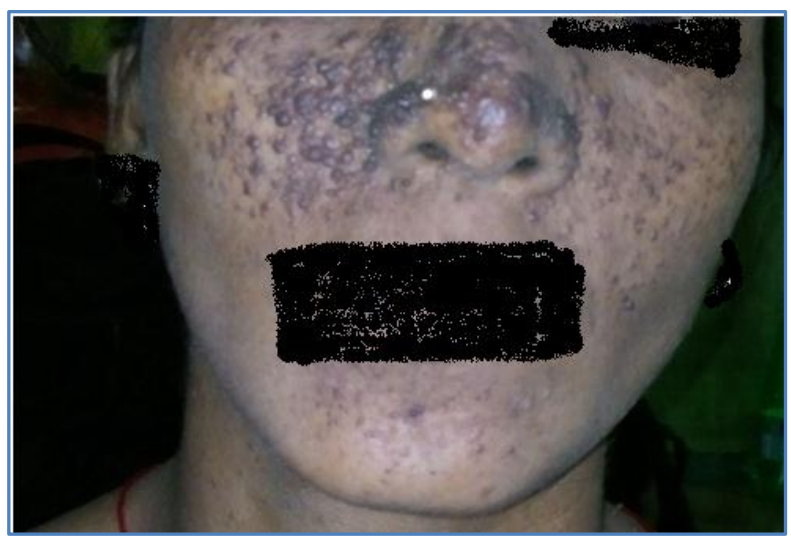




\section{CASE REPORT}
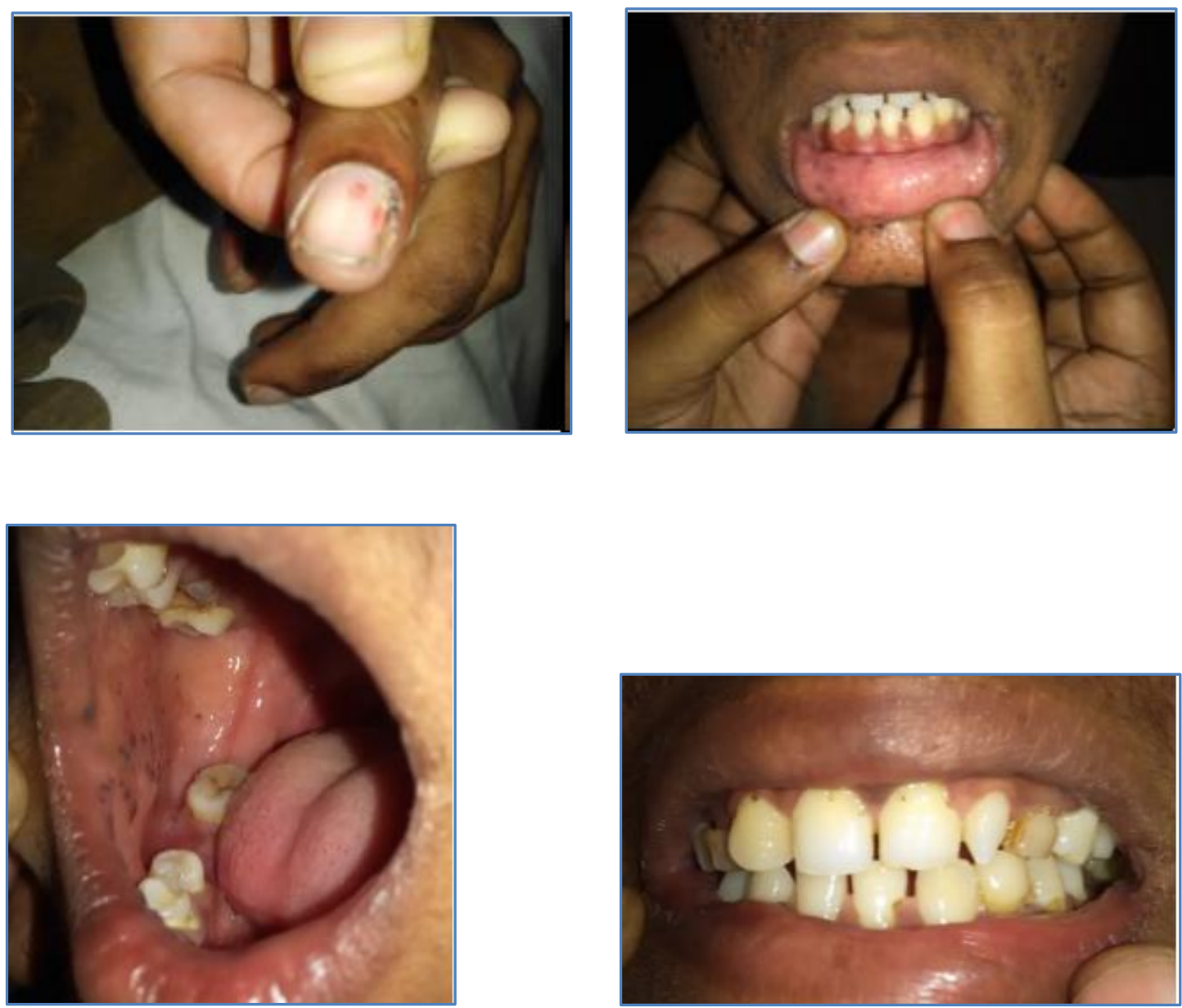

Fingers show periungual fibromas. There are oral labial mucosal fibromas, buccal fibromas and multiple dental pits.

Ophthalmic Examination: On examination, her best corrected visual acuity was 20/20, N6. The anterior segment in both eyes was within normal limits. Fundus shows multiple retinal astrocytic hamartomas in both eyes. The lesions in this patient are presented as classical multiple, slightly elevated, creamy white and well circumscribed.(2) They are obscuring the retinal vessels.(3) 


\section{CASE REPORT}

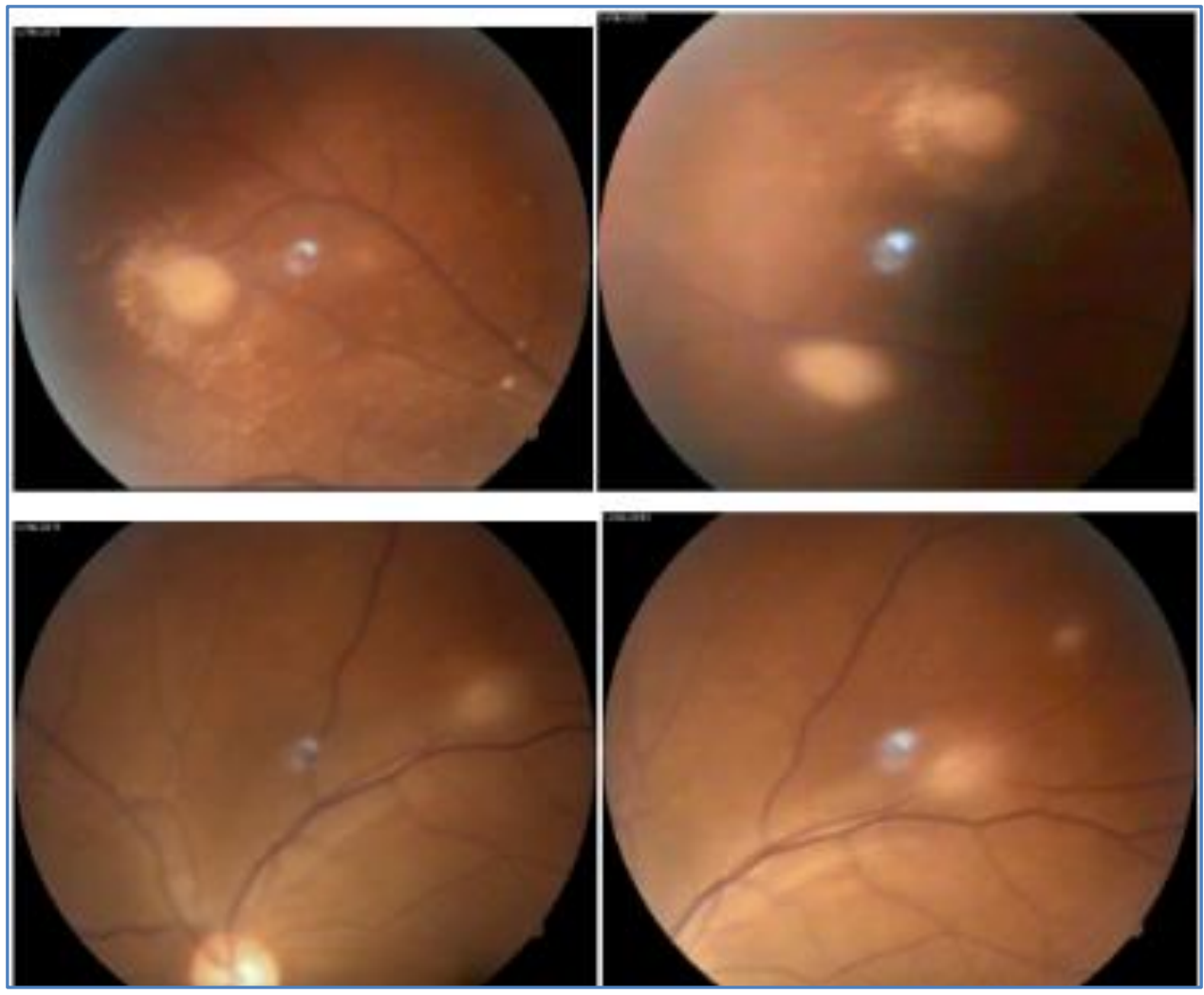

Other Investigations: Ultrasound abdomen showed B/L multiple angiomyolipoma with hamartomatous mass lesion from right kidney and $\mathrm{B} / \mathrm{L}$ ovarian cyst.

CT abdomen shows B/L renal angiomyolipoma, Rt. Sided renal lesion associated with fairly large solid mass? myoma of size $10 \times 9 \mathrm{~cm}$.

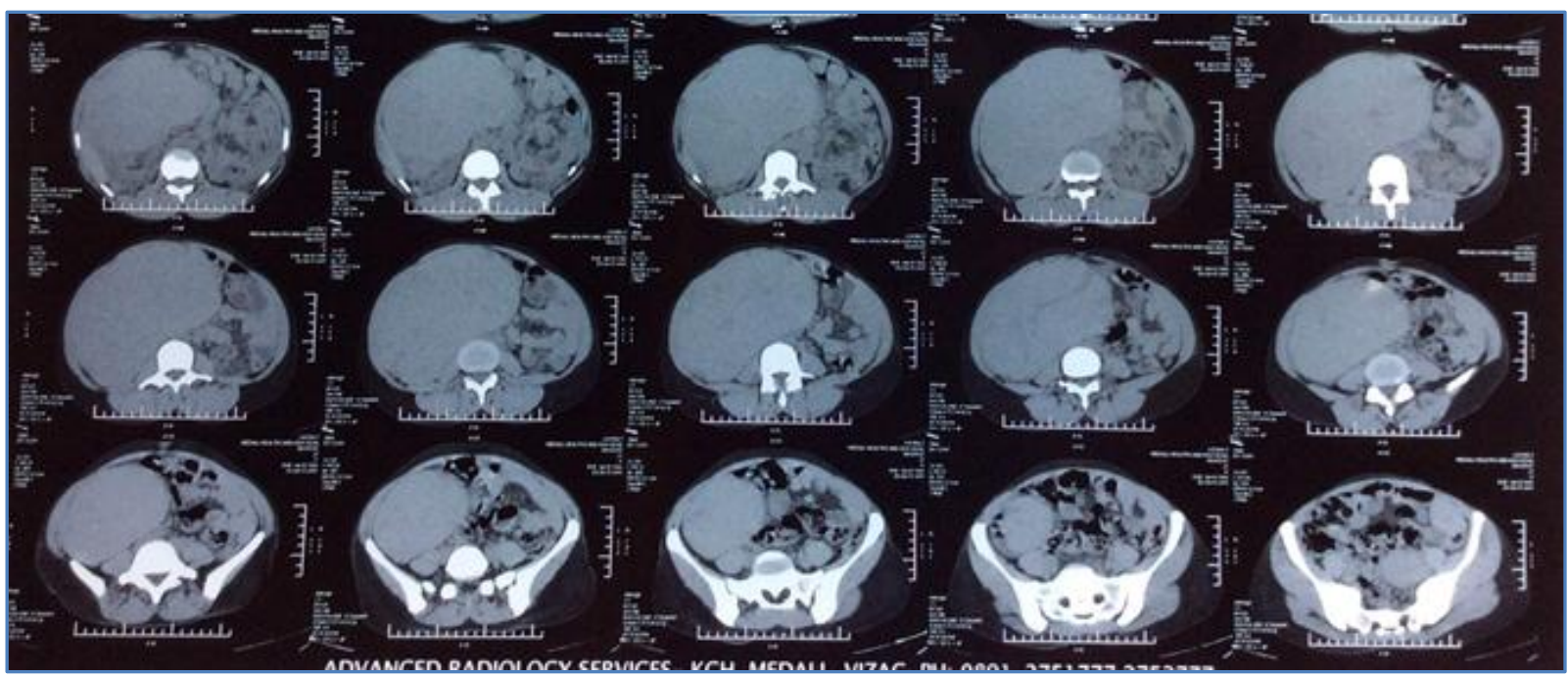




\section{CASE REPORT}
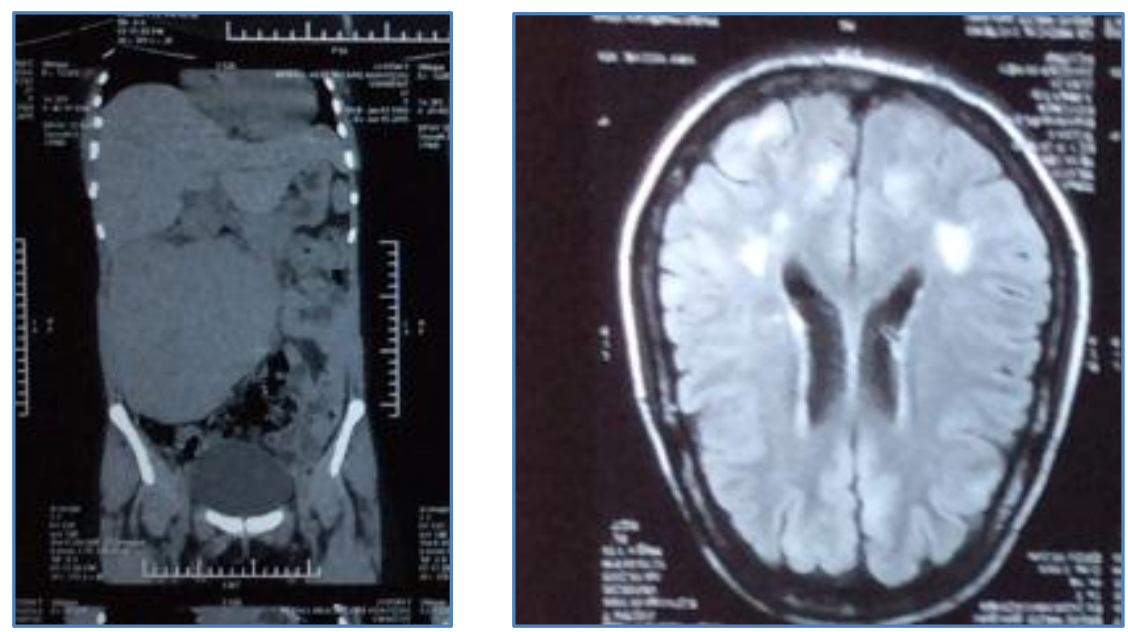

MRI of brain shows presence of multiple cortical tubers, subependymal nodules and subependymal calcific lesions.

DISCUSSION AND CONCLUSION: This case report is a good example of complex nature of Tuberous sclerosis. The diagnosis and management of these patients depends on presentation of disease.

For retinal astrocytic hamartomas, treatment is almost never required, with the rare exception of growing lesions, where photodynamic therapy can be effective. On rare occasions retinal astrocytomas can show progressive growth and have associated features such as vitreous seeds, vitreous hemorrhage and exudative retinal detachment, which can simulate retinoblastoma or choroidal melanoma.(3)

\section{REFERENCES:}

1. Eagle RC, Jr, Shields JA, Shields CL, Wood MG. Hamartomas of the iris and ciliary body epithelium in tuberous sclerosis complex. Arch Ophthalmol. 2000; 118: 711-5. [PubMed].

2. Nyboer JH, Robertson DM, Gomer MR. Retinal lesions in tuberous sclerosis. Arch Ophthalmol.1976; 94: 1277-80. [PubMed].

3. Nikolaos E. Bechrakis, MD; Klaus-Martin Kreusel, MDFaculty and Disclosures CME Released: $06 / 27 / 2011$. 


\section{CASE REPORT}

\section{AUTHORS:}

1. G. Premalatha

2. V. Rajeswara Rao

3. K. Padmavathi

\section{PARTICULARS OF CONTRIBUTORS:}

1. Assistant Professor, Department of Ophthalmology, Andhra Medical College, Visakhapatnam, Andhra Pradesh.

2. Professor, Department of Ophthalmology, Andhra Medical College, Visakhapatnam, Andhra Pradesh.

FINANCIAL OR OTHER

COMPETING INTERESTS: None
3. Assistant Professor, Department of Ophthalmology, Andhra Medical College, Visakhapatnam, Andhra Pradesh.

\section{NAME ADDRESS EMAIL ID OF THE} CORRESPONDING AUTHOR:

Dr. G. Premalatha,

1-68-22/1,

Sector 2, M. V. P. Colony,

Visakhapatnam-530017,

Andhra Pradesh.

E-mail: docpjs@gmail.com

Date of Submission: 21/06/2015.

Date of Peer Review: 23/06/2015.

Date of Acceptance: 06/07/2015.

Date of Publishing: 09/07/2015. 